\title{
CINCO EXPLICAÇÕES SOBRE A CRISE DA ALIANÇA ENTRE A ESCOLA E A FAMÍLIA
}

\author{
FIVE EXPLANATIONS ON THE CRISIS OF THE ALLIANCE BETWEEN THE SCHOOL AND THE FAMILY \\ CINCO EXPLICACIONES SOBRE LA CRISIS DE LA ALIANZA ENTRE LA ESCUELA Y LA FAMILIA
}

\author{
NARODOWSKI, Mariano 1 \\ ARIAS, María Eugenia ${ }^{2}$
}

\section{RESUMO}

Este trabalho tem como objetivo analisar os problemas da aliança entre escola e família no contexto de grandes transformações tecnológicas e das mutações das relações sociais nas últimas décadas, que colocaram em crise pedagógica velhas certezas. Neste artigo, a partir do trabalho teórico, desejamos propor cinco explicações sobre as dificuldades na aliança entre a escola e a família, oferecendo, na última delas, algumas vias para pensar a prospectiva do problema de uma maneira criativa e útil ao trabalho cotidiano dos educadores, superando, por um lado, o olhar nostálgico que pretende voltar à velha aliança e, por outro, o olhar clientelista, que decidiu anular o pensamento e adaptar-se ao cliente, adaptando as escolas não aos alunos, mas aos clientes.

Palavras-chave: Aliança escola família. Crise. Transformações sociais.

\section{ABSTRACT}

The objective of this work is to analyze the problems of the school-family alliance in the context of the great technological transformations and the mutations of the social relations of the last decades, which have put in crisis the old pedagogical certainties. To do this, five explanations about the difficulties in the relationship between the family and the school were synthesized, offering, in the last one, some ways to think about the prospect of the problem in a creative and useful way to the work of the educators, surpassing, on the one hand, the nostalgic look that seeks to return to the old alliance and, on the other hand, the clientelist look that decided to neglect the thought and adapt the school not to students but to clients.

Keywords: Alliance school family. Ccrisis. Social transformations.

\section{RESUMEN}

Este trabajo tiene como objetivo analizar la problemática de la alianza entre la escuela y la familia en el contexto de las grandes trasformaciones tecnológicas y las mutaciones de las relaciones sociales de las últimas décadas, que han puesto en crisis las viejas certezas pedagógicas. Para ello, se sintetizaron cinco explicaciones sobre las dificultades en la relación entre la familia y la escuela ofreciendo, en la última de ellas, algunas vías para pensar la prospectiva del problema de una manera creativa y útil al trabajo de los educadores, superando, por una lado, la mirada nostálgica que pretende volver a la vieja alianza y, por otro lado, la mirada clientelista que decidió anular el pensamiento y adaptar la escuela no a alumnos sino a clientes.

Palabras clave: Alianza escuela familia. Crisis. Transformaciones sociales.

\footnotetext{
1 Universidade Torcuato Di Tella - UTDT - Buenos Aires - Argentina

2 Universidade Austral - UA - Buenos Aires - Argentina
} 


\section{INTRODUÇÃO}

Nos últimos anos tem crescido uma sorte de clamor global por parte de muitos educadores: as famílias se sublevam, se queixam, não atendem as indicações dos docentes, os pais dão a razão a seus filhos antes que aos mestres da escola, não se interessam muito pela atividade escolar, ameaçam aos professores e chegam até a violência física, como seguidamente é mostrado pelos meios de comunicação em muitos países do mundo (LÓPEZ \& PÉREZ, 2006).

Este é um fenômeno da chamada cultura ocidental que, com diferente magnitude e com distintas características, dá-se em muitos países do mundo mesmo a pesar das divergências políticas, económicas, culturais e religiosas. Um fenômeno que se traduz muitas vezes na busca de diversas estratégias e programas, e em alguns casos no desenvolvimento de políticas educativas que têm como objetivo solucionar os problemas cada vez mais recorrentes entre a escola e a família (MAPP \& KUTTNER, 2013)3.

Uma parte desta questão está evidentemente vinculada às mudanças na transmissão intergeracional (MEAD,1978), que já foi analisada em outros textos: é evidente a existência de um câmbio cultural nas relações entre as gerações mais velhas e as gerações mais jovens e a ideia de adulto responsável, comprometido e sacrificado está em franca retirada a favor de adultos que crescentemente se liberam de suas antigas obrigações parentais (NARODOWSKI, 2016).

Estas mutações também se evidenciam na ocorrência de grandes mudanças na estrutura das famílias, dando origem a novas formas de famílias com estilos parentais de criação diversos. Golombok (2016), aponta que o advento destas novas formas de famílias tem limitado a relevância quantitativa da denominada "família tradicional" composta por um casal heterossexual com filhos biologicamente emparentados ${ }^{4}$. Paradoxalmente, essa família tradicional, no sentido de Golombok e homogénea parece ser a "esperada" pela maioria dos educadores (EPSTEIN, 2011). Nesse sentido, a investigação realizada por López \& Pérez (2006, p. 105) aponta:

\footnotetext{
3 Nesta linha pode mencionar-se o "Dual Capacity-Building Framework for Family-School Partnership", desenhado e adotado pelo Departamento de Educação de Estados Unidos em 2013. Este modelo funciona como uma espécie de guia sobre a qual se "estabelecem as bases ou os princípios fundamentais que devem reunir qualquer tipo de estratégia que tenha como propósito comprometer a família na educação" (MAAP \& KUTTNER, 2013, p. 6).

${ }^{4}$ As investigações de Suan Golombok apontam a estudar o impacto das novas formas de família na criação dos filhos e o desenvolvimento infantil, especificamente as famílias de mães lesbianas, as famílias de pais homossexuais, as mães solteiras por opção e as famílias criadas por tecnologias de reprodução assistida, incluindo fertilização in vitro, inseminação de doadores e doação de óvulos. Golombok afirma que "os aspectos estruturais da família, como o número, o género, a orientação sexual e a relação genética dos pais, são menos importantes para o bem-estar psicológico das crianças que a qualidade das relações familiares" (GOLOMBOK, 2016, p.235).
} 
(...) é necessário considerar a discrepância que existe entre o modelo de família ao qual se apela desde as instituições escolares - em termos de apoio material, de seguimento, de acompanhamento, de presença nos distintos eventos- e a crescente diversidade de grupos domésticos que atualmente vive na área metropolitana bonaerense, discrepância que gera uma profunda brecha entre as expectativas e interesses da escola e dos pais.

Outra parte do problema tem a ver com a escola e os docentes: a situação atual da instituição escolar moderna não é a mesma que séculos atrás quando a escola nasceu e se fez útil à sociedade. Só a ideia de uma sociedade disciplinaria, hierárquica, na qual a escola exercia o monopólio do saber legítimo, choca com uma sociedade caracterizada pela desaparição da alteridade e a estranheza e na que a hibridação parece constituir o fator central (HAN, 2012). Há mais de trinta anos, Neil Postman (1982) já explicava como a generalização da televisão (hoje diríamos as telas em rede) iria ocupar o núcleo central do saber legítimo pondo em posição de equivalentes a adultos com crianças.

Neste contexto, um grande erro de muitos educadores é pretender que o que antes sucedia era o "natural", o "normal" ou o que "deve ser" das escolas, sem compreender que profundas transformações tecnológicas, mas especialmente nas relações sociais, têm colocado em crise às velhas certezas pedagógicas que faziam a configuração do escolar (WARDE, 2001; NARODOWSKI, 2016).

Neste artigo, a partir do trabalho teórico, desejamos propor cinco explicações sobre as dificuldades na aliança entre a escola e a família, oferecendo, na última delas, algumas vias para pensar a prospectiva do problema de uma maneira criativa e útil ao trabalho cotidiano dos educadores. A partir da revisão da pesquisa recente e do consenso básico de um grupo de autores que postulou a crise da aliança entre a escola familiar, o objetivo é construir dimensões que permitam uma ampla visão das possibilidades e limites desse dispositivo.

Não é, portanto, uma abordagem moral para estabelecer avanços ou contratempos, mas sim a abertura de cenários que, mesmo com seu caráter teórico e provisório, permitem compreender a densidade dos desafios do presente.

\section{A RELAÇÃO ENTRE A ESCOLA E A FAMÍLIA NÃO É "NATURAL"}

Apesar dos grandes avanços tecnológicos e as profundas transformações sociais das últimas décadas, as famílias continuam enviando as crianças e os jovens a instituições escolares para a transmissão do conhecimento. Crianças e jovens seguem indo às escolas para aprender, tal como vem ocorrendo aproximadamente há 300 anos (NARODOWSKI, 2016).

Talvez por isto, o traslado do corpo infantil desde o âmbito familiar à instituição escolar se apresenta - a priori - como um fenómeno natural e inerente à educação da infância. Mas analisando-o desde uma perspectiva histórica de longa duração, podemos ressaltar os acontecimentos relevantes que permitem compreender que a relação entre a escola e a família se encontra nas antípodas de "o natural" e que ela obedece a tensões contingentes que limitam, talvez incondicionalmente, sua história. 
Por um lado, a aparição do homo sapiens-sapiens (que, segundo investigações recentes, se estima em uns 200.000 anos de antiguidade), que poderia identificar-se como o ponto de partida, sempre provisório, relativo e por certo arbitrário, do que hoje reconhecemos como o fenótipo humano (HARARI, 2014). Por outro, a aparição da escola moderna formulada por Comenius no século XVII, mas implementada recém a partir do século XIX: uma tecnologia de saber-poder que permitira, como nunca antes, alfabetizar a ingentes e cada vez maiores massas populacionais (NARODOWSKI, 2001).

A interação entre ambos fatos permite vislumbrar que só durante uma minúscula porção de tempo os seres humanos aprendemos em escolas: a transmissão do conhecimento não teve lugar em escolas durante a maior parte da história da humanidade (ONG, 2013), o que significa que a relação entre a escola e a família também foi um fenómeno especificamente moderno.

A aparição da escola de assistência obrigatória para todas as crianças gerou um problema social de envergadura: enormes massas de crianças deveriam deslocar-se todos os dias desde seus lares familiares até as escolas. Uma mudança enorme na engenharia social que se produziu ao longo de todo o século XIX e inícios do XX e que, longe de ser natural, gerou muitos conflitos (NARODOWSKI \& CARRIEGO, 2006).

Em muitos casos, os pais não queriam seus filhos nas escolas. Os registros discursivos eram diversos e as razões várias: porque restavam braços para a produção, porque a educação que receberiam não era a adequada, porque a organização da escola lhe lembrava à organização dos exércitos e supunham que se tratava de outra leva compulsiva, porque a escola oferecia uma ideologia alheia aos interesses das famílias proletárias ou porque - simplesmente - não achavam oportuno que um estranho educasse seus filhos (FERNANDEZ ENGUITA, 1985).

Estas resistências que apresentavam as famílias frente à escolarização da infância põe em evidência que o vínculo entre a família e a escola não se deu como um fenómeno natural, voluntário e inerente à mesma escolarização senão que foi um fato imposto à família e como tal muito resistido. É de tal maneira que "os estados tiveram que recorrer a leis de obrigatoriedade escolar para garantir o comparecimento das crianças à escola". Mesmo que o direito à educação tenha sido consagrado pela constituição francesa de 1791 e replicado por diversos textos legais, somente depois de um século dessa data liminar a escola obrigatória passou a ser percebida como um "direito" por parte da população e assim os pais aceitaram estabelecer uma aliança entre a escola e as famílias.

\section{A ALIANÇA ENTRE A ESCOLA E A FAMIÍLA IMPLICAVA EM OBRIGAÇÕES}

O traspasso da educação familiar à educação escolar irá se efetivar a través do dispositivo de aliança escola e família, ou seja, através de um contrato mais ou menos tácito entre os que estão "naturalmente" encarregados do filho (os progenitores) e os que estão "efetivamente" encarregados do aluno (os professores) (CARRIEGO, 2010). 
Os limites entre a escola e a família estavam claros e bem delimitados. O que correspondia à escola e à família foi claramente estabelecido no discurso pedagógico moderno e regulado pela aliança: como todo contrato, também o dispositivo de aliança construído na pedagogia moderna estipulava o que podiam e o que não podiam fazer os pais e os professores a respeito da educação dos filhos e alunos.

Pois bem, esta aliança se sustentava em base a duas condições. Por um lado, as escolas deveriam desenvolver um ensino que superasse os saberes que as crianças conseguissem no lar. Com profissionais especializados - os professores- a educação escolar deveria ser melhor que a educação do lar ou, dito de outra maneira, deveria concitar uma maior legitimidade.

Assim, o filho convertido em aluno terá melhores possibilidades para aprender esses saberes socialmente legitimados. Os pais deverão entregar seus filhos à escola para a transmissão do conhecimento, dado que a instituição escolar estará em melhores condições que a família para a educação das crianças. Os pais (tradicionalmente o pai) deixa de exercer seu poder sobre o filho para que este, já como aluno, seja educado corretamente numa escola, sob a autoridade de um professor.

\footnotetext{
Já não é suficiente a ação do pai ou da mãe para educar corretamente os filhos e filhas, são os novos especialistas (educadores e educadoras profissionais) quem, com métodos racionais, atuarão sobre o menino e a menina que, por sua vez, não seguirão sendo somente um menino ou uma menina, senão que passarão a ser um "menino aluno" ou uma "menina aluna" (NARODOWSKI \& CARRIEGO, 2006, p.13).
}

Ali radica a legitimidade dos educadores. Se trata de uma legitimidade de origem, dada pelo lugar que ocupam e pela unânime suposição por sua expertise profissional. São agora os professores, e não os pais, os especialistas que terão ao seu encargo a educação da infância e assim ocuparão o lugar indiscutido do saber (CARRIEGO, 2010).

Por outro lado, frente a qualquer situação de conflito, este se dirimia a favor da escola: ou seja, que frente a um virtual desajuste entre as diretivas docentes e as das famílias ou entre a cultura escolar e a cultura familiar ou popular, o conflito devia resolver-se a favor de professores e escolas. Desta maneira, o caráter monopólico do saber escolar se delatava frente a uma crise na qual entravam em conflito os saberes escolares e os saberes familiares: em caso de conflito, o(a) menino(a) somente poderia ser escolarizado se seus pais e ele(a) mesmo(a) se ativessem ao que demarcava a cultura escolar.

As famílias, nesta aliança, eram um sujeito passivo que se ajustava às regularizações escolares. A aliança implicava una assimetria entre a escola e a família - indispensável - para a tarefa educadora da escola: os educadores ocupavam o lugar do adulto que sabe, um lugar diferente ao da família e inverso ao lugar do aluno, ocupado por uma criança que não sabe que no máximo é portador de saberes vulgares que é necessário arrancar e substituir. 
Este cenário onde a escola dispunha e a família acatava sem maiores questionamentos era possível porque a escola estava legitimada como a única instituição capaz de transmitir o conhecimento e os educadores detectavam o lugar indiscutido do saber. As escolas foram ferramentas de civilização.

\section{NÃO É FÁCIL RESISTIR HOJE ÀS DUAS CONDIÇÕES DA ALIANÇA}

Primeiro, porque a velha aliança escola-família reinava omnipotente em épocas em que as escolas eram a única fonte do conhecimento, o lugar monopólico de distribuição do saber. Hoje, o saber está facilmente disponível em redes e telas e inclusive pode-se obtê-lo mais puro e atualizado mais fora do que dentro da escola (POSTMAN, 1982).

Se o saber está disponível em múltiplos cenários, e se estende ao longo de toda a vida, além dos limites temporais da escolaridade, já não é a escola a única instituição capaz de brindar aprendizagens válidas à infância. A cultura extraescolar toma uma força preponderante frente à cultura escolar, que se percebe obsoleta e imóvel frente à mudança. Cada um dos docentes tem que sair a ganhar sua própria legitimidade todos os dias e constantemente, uma vez que a cultura extraescolar passou a ocupar lugares de grande significação na vida cotidiana e até se supõe óbvio e construtivo o questionamento por parte da cultura popular à cultura escolar.

Cada um dos dispositivos escolares que conformaram a escola da modernidade: instrução simultânea, simultaneidade sistémica, a escola como lugar de encerro e também a aliança escolafamília são discutidos e questionados permanentemente. Versa sobre eles uma reclamação persistente para ser substituídos por outro formato completamente novo (NARODOWSKI, 2016). Assim o refletem a quantidade e diversidade dos novos - e velhos - projetos de inovação. Os mais audazes intentam a rotura (falida muitas vezes) dos velhos dispositivos da modernidade.

Segundo, porque a autoridade docente que transmitia ser a única fonte de conhecimento hoje está pulverizada em relações sem hierarquias, que causam uma profunda crise de legitimidade. $O$ aplanamento nas relações intergeracionais (MEAD, 1978) tem um efeito devastador na autoridade e legitimidade adulta pelo que resulta difícil construir o lugar do loco parentis (o lugar do professor na escola é a transferência do pai), já que o caráter adulto da paternidade já vem desvalorizado e a transferência desse perfil desvalorizado ao mundo escolar não melhora, de maneira alguma, a legitimidade adulta.

Hoje, a assimetria indispensável para a tarefa educadora se encontra diluída em relações de equivalência, entre iguais. Há um corrimento - rotundo e muitas vezes dramático para os educadores da centralidade do professor como adulto que sabe.

Por isso, frente à emergência de um conflito entre a escola e a família, já ninguém atina a saber como vai se resolver, que lógica vai preponderar, quem vai prevalecer. A época onde a escola dispunha e a família acatava sem questionamento tem chegado ao seu fim. Esta é a época da 
imprevisibilidade, da incerteza; já não existe nem a certeza nem a segurança de antes, onde o conflito era dirimido a favor dos educadores. Enquanto que na escola da modernidade os conflitos se dirimiam a favor de uma cultura escolar - porque a cultura escolar era a cultura legítima -, hoje a simples situação de conflito não tem, entre a cultura escolar e a cultura popular, uma resolução única e previsível (CARRIEGO, 2010).

Não é que a autoridade docente tenha desaparecido senão que se tem transformado. Tem passado de uma autoridade de "origem" que estava dada pelo lugar de saber que ocupava a uma autoridade de "exercício": os docentes temos que sair a demostrar a vigência de nossa atividade. Como foi assinalado antes, a legitimidade do docente deve ser corroborada continuamente. A única autoridade adulta que vale é a que é capaz de relegitimar de forma contingente certos vestígios da alteridade assimétrica, mesmo que a tarefa seja gigantesca e deva ser reiniciada a cada momento.

\section{A ALIANÇA ESCOLA-FAMÍLA NÃO DESAPARECE, SE INVERTE}

Além das críticas vertidas à escola atual que apontam à obsolescência dos dispositivos que medularmente a conformam, a instituição escolar ainda resiste. Resistência reforçada especialmente no dispositivo de aliança escola família: ainda hoje as famílias seguem entregando o corpo de crianças e jovens à escola tal como o vêm fazendo desde a aparição mesma da instituição escolar.

Originais projetos inovadores - de hoje e de ontem - propõem mudanças radicais em vários dos dispositivos. Mas poucos como o movimento Homeschooling (educação no lar) ou o recente Projeto $\mathrm{COOL}^{5}$ (de Nova Zelândia) propõem uma rotura profunda na escola como lugar onde se aprende, lugar de encerro e no dispositivo de aliança.

Se a família já não tivesse que entregar as crianças à escola, como seria a organização social sem contar com a escolarização da infância? Na medida em que se necessite do fluxo de crianças dos lares às escolas, a aliança escola-família é indispensável não somente para cumprir com a promessa de educar à infância, senão que é imprescindível devido ao tipo de organização social na que vivemos: que faria o mundo adulto com grandes quantidades de crianças e jovens sem o resguardo da escola?

A proibição do trabalho infantil e a necessidade dos progenitores de constituir-se em força de trabalho independente do lar configura a necessidade do controle bio-político do corpo infantil, expressado no cuidado adulto por meio de escolas.

\footnotetext{
${ }^{5}$ Em 22 de agosto de 2016, Hekia Parata, Ministra de Educação de Nova Zelândia, apresentou O Projeto COOL (Communities of Online Learning). Este projeto de lei propõe um sistema educativo digital alternativo e complementário ao tradicional. Se este projeto é finalmente aprovado, as famílias poderão optar entre educação on line ou educação em escolas físicas para seus filhos. Em outras palavras, todos os alunos neozelandeses, desde o jardim de infância até o último ano do ensino médio, poderiam cursar seus estudos mediante a modalidade online, sem obrigação de frequentar um estabelecimento escolar. Disponível em:http://ar.bastiondigital.com/notas/haciala-vanguardia-educativa. Acceso em: 15 de jun. 2017.
} 
Se bem a aliança escola-família seja indispensável (ao menos por enquanto), já não pode funcionar como o fazia na escola da modernidade. Tem tido tendência a inverter seu sentido: já não é a família a que se adapta à escola senão as escolas as que crescentemente se ajustam às demandas das famílias.

$\mathrm{Na}$ atualidade, a aliança se sustenta sobre a base de um reconhecimento inverso ao anterior: é a cultura escolar a que está posta na mira, acusada de anacronismo, despotismo e rigidez. E se o dispositivo de aliança escola-família ainda se conserva é porque, apesar do desprestígio da instituição escolar, a pedagogia indica ao educador que deve "adaptar-se", "tolerar", "compreender" as diferenças culturais de raça, etnia, história, classe, gênero (SILVA, 2017).

Por isso, o critério que, gradualmente, mesmo inconfessavelmente, adotam as escolas, se enquadra numa lógica de mercado "satisfação do cliente": tudo está bem se as famílias estão satisfeitas, conformes (GREEN, 2005). "A escola hoje busca "customizar" sua oferta; ou seja, adaptá-la a seus clientes e centrá-la nos interesses da demanda" (NARODOWSKI \& CARRIEGO, 2006, p. 17).

Este funcionamento de clientelismo tende a evitar todo o conflito. Conflito que, como vimos, gera incerteza e tensão nos educadores, pois ninguém prediz como se resolve. Os conflitos que não se enfrentam, longe de desaparecer, se acentuam e embaçam ainda mais a confiança entre escola e família (LÓPEZ \& PÉREZ, 2006). Isto não ocorre somente em escolas privadas: escolas públicas gratuitas que atendem a setores muito pobres também acolhem o modelo de clientelismo, ao igual que os funcionários políticos, assustados como estão de não saber como enfrentar pressões irresolúveis.

\section{A SAUDADE NÃO É A SOLUÇÃO O CLIENTELISMO TAMPOUCO}

Como foi descrito, a atual conformação da aliança escola-família se encontra atravessada pelo conflito e enquadrada numa espécie de relação de clientelismo, com expectativas, reclamações, demandas e exigências das famílias em constante aumento, algumas das quais geram cenários violentos.

Os limites e fronteiras entre escola e família estão confusos (LÓPEZ \& PÉREZ, 2006), a autoridade adulta de docentes e pais apagada (NARODOWSKI, 2016), há grandes mudanças na composição das famílias e novos estilos parentais de criação (GOLOMBOK, 2016) que se traduzem num verdadeiro desafio profissional para os educadores.

Se ensaiam diversas respostas para tratar de resolver a grande quantidade de conflitos que opera entre a escola e a família. Algumas se fundamentam na esperança de reconstruir um passado que já não tem possibilidades de reinstalar-se, o que provoca um círculo de desgaste e frustração nos educadores.

Outras intentam abrir a escola aos pais. Há tentativas de "empoderar às famílias", fazê-las "sócias" dos educadores (MAPP \& KUTTNER, 2013). Pareceria que estes postulados diluem ainda mais a assimetria, mesmo que continuem sendo estratégias, esforços dos educadores para 
reconfigurar a aliança perdida. Se intenta consolidar instâncias de participação familiar talvez mais interessantes e comprometidas para a família (algumas com capacidade de decidir em questões pedagógicas). Estas estratégias se fundamentam em vários estudos que vêm demonstrando que quando a família participa (se fundamentalmente a escola habilita espaços para isso), se compromete e isto impacta na aprendizagem do aluno. (HENDERSON \& MAAP, 2002; GIGAGLIA \& LLACH, 2009; HENDERSON et al. 2007; EPSTEIN, 2011).

Mas, como vimos, a aliança que nasceu com a escola da modernidade hoje já não é possível de ser sustentada. Então... o que fazer? É difícil dar uma resposta adequada, embora os dois cenários típicos não ajudem muito. Por um lado, o nostálgico (BOYM, 2002), que pretende voltar à velha aliança, é inconsistente e ineficaz. Inconsistente porque não é possível aceitar agora que a escola de um século atrás fosse a que queríamos, só para concentrar autoridade. Ineficaz, porque a volta atrás não existe, não dá nenhum resultado: não é possível voltar a mudar o que já mudou.

Por outro lado, o clientelista, que decidiu anular o pensamento e adaptar-se ao cliente, tem, lamentavelmente, mais chances de sucesso, mas a um custo muito alto: diluir-se em demandas cambiantes e aguacentas que vão transformando o educador num mero mediador entre os saberes e os alunos: é a morte simbólica do educador (LYOTARD, 1984; SCIALABBA, 2004).

Ser educador, não entanto, é ser um outro claro e diferente com algo inovador para colocar, com algo diverso para mostrar. $E$ isto, certamente, não está isento de conflitos.

Como enfrentá-los no século XXI é o grande desafio dos docentes de agora e dos que virão: se trata de dotar os futuros docentes de ferramentas que lhes sirvam desde o ponto de vista atitudinal para sentir-se confortáveis no conflito, para não vê-lo como uma anomalia por sua inação ou consequência de um defeito social retificável, senão como uma marca própria dos tempos e da atual fase do processo de escolarização.

Nota:

Os autores agradecem o apoio de Silvia Molinari na tradução para o português e o entusiasmo e apoio de Viviane Castro Camozzato e Rochele Santaiana (professoras da Universidade Estadual do Rio Grande do Sul / UERGS), essenciais para a conclusão deste artigo. 


\section{REFERÊNCIAS}

1. BOYM, Svetlana. The future of nostalgia. Cambridge: Basic Books, 2002.

2. CARRIEGO, Cristina B. La participación de las familias: injerencia en la gestión y apoyo al aprendizaje. Revista Iberoamericana sobre Calidad, Eficacia y Cambio en Educación, Madrid: RINACE, v.8, n. 3, p. 50-57, feb. 2010.

3. EPSTEIN, Joyce L. School, Family and Community Partnerships: preparing educators and improving schools. 2. ed. Boulder: Westview Press, 2011.

4. FERNÁNDEZ ENGUITA, Mariano. Trabajo, escuela e ideología: Marx y la crítica de la educación. Madrid: Ediciones AKAL, 1985.

5. GREEN, Jay P. Education Myths: what special interest groups want you to believe about our schools--and why it isn't so. New York: Rowman \& Littlefield Publishers, 2005.

6. GOLOMBOK, Susan. Familias Modernas: padres e hijos en las nuevas formas de familia. Madrid: Siglo XXI de España Editores, 2016.

7. HAN, Byung-Chul. La sociedad del cansancio. 6. ed. Barcelona: Herder Editorial, 2012.

8. HARARI, Yuval N. Sapiens: de animales a dioses. Barcelona: Debate, 2014.

9. HENDERSON, Anne T. et al. Beyond the Bake Sale: the essencial guide to family-school partnerships. New York: The New Press, 2007 .; MAPP, Karen L. A New Wave of Evidence: the impact of school, family and community connections on student achievement. Austin: SEDL, 2002.

11. LIACH, Juan; GIGAGLIA, Maria E. La participación de las familias en las escuelas públicas del nivel primario y medio: el rol de las cooperadoras y otras formas de integración. Buenos Aires: IAEFundación Avina, 2009. Disponível em: https://es.slideshare.net//AEaustral/la-participacin-de-las- 
familias-en-las-escuelas-pblicas-del-nivel-primario-y-medio-el-rol-de-las-cooperadoras-y-otrasformas-de-integracin. Acceso em: 10 de jun. 2017.

LYOTARD, Jean-Francois. The postmodern condition: a report on knowledge (Vol. 10). Mineápolis: University of Minnesota Press, 1984.

13. LÓPEZ, María M.; PÉREZ, Andrea V. Alianza Escuela-Familia en los bordes de lo escolar en el Gran Buenos Aires. Estudios Fronterizos, Méxicali: Universidad Autónoma de Baja California, vol.7 n. 013, ene/jun. 2006.

14. MAPP, Karen; KUTTNER, Paul. Partners in Education: a dual capacity-building framework for family-school partnership. Austin: SEDL, 2013.

15. MEAD, Margaret. Culture and commitment: the new relationships between the generations in the 1970s.New Yourk: Rev. Anchor Press/Doubleday, 1978.

16. NARODOWSKI, Mariano. Infância e poder: a conformação da Pedagogia Moderna. Bragança Paulista: Universidade São Francisco, 2001. Un mundo sin adultos: familias, escuela y medios frente a la desaparición de la autoridad de los mayores. Buenos Aires: Debate, 2016. .; CARRIEGO, Cristina B. La escuela frente al límite y los límites de la escuela. In: Ospina, H.F.; NARODOWSKI, M..; MARTINEZ BOOM, A. (Org.). La escuela frente al límite: actores emergentes y transformaciones estructurales. Buenos Aires: Novedades Educativas, 2006. 
21. SCIALABBA, Alejandra. ¿Se está muriendo la escuela?: la responsabilidad de la aparición de las nuevas tecnologías en la redefinición de la escuela. Revista Iberoamericana de Educación, Madrid: OEI, v. 33, jun. 2004.

22. SILVA, P. (2017). Análise sociológica da relação escola-família: um roteiro sobre o caso português. Sociologia. Revista da Faculdade de Letras da Universidade do Porto, Porto: Universidade do Porto, vol. 20. 2017.

23. WARDER, Mirian J. Childhood, School, and Family: continuity and displacement in recent research. In: HULTQVIST, K. \& DAHLBERG, G. (Org.). Childhood, School, and Family. Governing the child in the new millennium. New York: Routledge Falmer, 2001.

\section{Mariano Narodowski}

Doctor en Educación (Universidad Estadual de Campinas, Brasil). Profesor de la Universidad Torcuato Di Tella. Miembro de Pansophia Proyect.

\section{María Eugenia Arias}

Orientadora Familiar (Universidad Austral, Argentina). Coordinadora de la Diplomatura Relación Escuela Familia de la Universidad Austral. Miembro de Pansophia Proyect.

\section{Como citar este documento:}

NARODOWSKI, Mariano; ARIAS, María Eugenia. Cinco explicações sobre a crise da aliança entre a escola e a família. Reflexão e Ação, Santa Cruz do Sul, v. 27, n. 1, dez. 2018. ISSN $1982-9949$. Disponível em: <https://online.unisc.br/seer/index.php/reflex/article/view/9989>. Acesso em: doi:https://doi.org/10.17058/rea.v27i1.9989. 